REVISTA X, Curitiba, volume 13, n.1, p. 206-229, 2018.

Dossiê Especial: Português como Língua Adicional em contextos de minorias:

(co)construindo sentidos a partir das margens

BIZON \& DINIZ (Orgs.)

\title{
TRANSITANDO ENTRE A LIBRAS E O PORTUGUÊS NA SALA DE AULA: EM BUSCA DE ESTRATÉGIAS VISUAIS DE ENSINO DA LEITURA
}

\section{Shuttling between Libras and Portuguese in the Classroom: in Search of Visual Strategies for Teaching Reading}

\author{
Giselli Mara da SILVA, FALE-UFMG ${ }^{1}$
}

\begin{abstract}
RESUMO: Neste artigo, pretende-se discutir o ensino de leitura para surdos mediado pela língua de sinais. O trabalho parte de uma perspectiva holística de bilinguismo, considerando a mescla como um fenômeno natural do bilinguismo (GROSJEAN, 2008), que, no entanto, precisa ser examinado em contextos pedagógicos (SILVA, 2005; SILVA, 2010). Foi analisado um evento de ensino de leitura numa turma de alunos surdos e professora ouvinte do $9^{\circ}$ ano do Ensino Fundamental, buscando mostrar como professores e alunos precisam transitar entre a Libras e o português durante as aulas. A análise desse evento evidencia a complexidade do trabalho do professor de português para surdos, especialmente no que tange à forma como usa a língua de sinais para estimular o processo de construção de sentidos pelos alunos e explicar o conteúdo e os elementos linguísticos dos textos em português. Em seguida, apresenta-se a proposta de um paradigma visual de ensino da leitura cf. Andrews e Rusher (2010), o qual estabelece diferentes formas de lidar sistematicamente com o trânsito entre a língua escrita e a língua de sinais em termos de objetivos de ensino.
\end{abstract}

PALAVRAS-CHAVE: Leitura; Surdos; Português como Segunda Língua; Libras; Mesclas linguísticas; Estratégias Visuais.

ABSTRACT: In this paper, we intend to discuss the teaching of reading to deaf people, mediated by sign language. The research is based on a holistic perspective of bilingualism, considering the language mixing as a natural phenomenon of bilingualism (GROSJEAN, 2008), which needs to be examined in pedagogical contexts (SILVA, 2005; SILVA, 2010). A lesson on reading in a 9th grade classroom with deaf students and a hearing teacher was analyzed so as to show how teachers and students need to shuttle between Libras and Portuguese during classes. The analysis of this event evidences the complexity of the work of someone who teaches Portuguese to the deaf, especially regarding the way in which the teacher uses sign language to stimulate the students' process of meaning-making and to explain the content and linguistic elements of the texts in Portuguese. Next, a proposal is made for a visual paradigm for the teaching of reading cf. Andrews and Rusher (2010), which establishes different ways of dealing systematically with the transition between written language and sign language in terms of teaching objectives.

\footnotetext{
${ }^{1}$ Doutora em Estudos Linguísticos e professora adjunta na FALE-UFMG.

Email: gisellims@yahoo.com.br
} 
REVISTA X, Curitiba, volume 13, n.1, p. 206-229, 2018.

Dossiê Especial: Português como Língua Adicional em contextos de minorias:

(co)construindo sentidos a partir das margens

BIZON \& DINIZ (Orgs.)

KEY-WORDS: Reading; Deaf People; Portuguese as Second Language; Libras; Language Mixing; Visual Strategies.

\section{INTRODUÇÃO}

O ensino da língua oficial do país como segunda língua (L2) a aprendizes surdos é mediado geralmente pela língua de sinais (LS) da comunidade surda local, língua comumente utilizada por esses aprendizes nas interações face a face. Assim, a presença dessas duas línguas na sala de aula faz com que alunos e professores necessitem transitar entre elas de diferentes formas. No caso, por exemplo, do ensino da leitura a surdos brasileiros, professores e alunos leem textos em português e, para interagir com seus interlocutores durante as atividades de leitura, precisam usar a Libras para se referir ao texto escrito, seja em relação a sua forma ou a seu conteúdo. A forma como professores e alunos usam a LS em sala de aula tem sido foco de intenso debate, tendo em conta as consequências para a compreensão e a aprendizagem dos alunos surdos (LODI; HARRISON; CAMPOS, 2002; BOTELHO, 2002; LODI, 2006; SILVA, 2010).

Considerando então estudos que problematizam o trânsito entre a Libras e o português no processo de ensino-aprendizagem da leitura para os surdos, neste trabalho, pretendemos: (i) por meio da análise de um evento em sala de aula, observar como professores e alunos lidam com as diferenças entre Libras e português; (ii) por meio da análise da literatura na área, apresentar uma possibilidade de uso de técnicas de ensino planejadas de forma a tornar o trânsito entre as línguas uma estratégia consciente por parte do professor.

É importante esclarecer que as técnicas de ensino de leitura a serem discutidas tomam como base os estudos sobre o bilinguismo, mais especificamente o bilinguismo dos surdos, considerando as mesclas como fenômenos linguísticos naturais (cf. GROSJEAN, 2008). Porém, é necessário considerar as consequências do uso de mesclas em contextos pedagógicos e a importância da definição de estratégias didáticas conscientes dessa relação entre as línguas em ambientes bilíngues (SILVA, 2005).

Dessa forma, este trabalho busca apresentar estratégias de ensino relacionadas à proposta de um paradigma visual de ensino da leitura (ANDREWS; RUSHER, 2010), 
REVISTA X, Curitiba, volume 13, n.1,p. 206-229, 2018.

Dossiê Especial: Português como Língua Adicional em contextos de minorias:

(co)construindo sentidos a partir das margens

BIZON \& DINIZ (Orgs.)

que explora, de diferentes formas, o uso da LS para se referir ao texto escrito. Destacase também que inúmeros trabalhos denunciam os baixos níveis de leitura dos aprendizes surdos, tanto no exterior como no Brasil (CAPOVILLA; CAPOVILLA; MACEDO 2007; HOFFMEISTER; CADWELL-HARRIS, 2014; entre outros), o que evidencia a importância da discussão desta temática. Cabe ressaltar ainda que a leitura assume mais importância no caso dos surdos, já que é, principalmente por ela, que esses aprendizes adquirem visualmente a língua escrita.

\section{ENSINO-APRENDIZAGEM DA LEITURA NO CASO DOS SURDOS}

Nos últimos anos, têm surgido propostas que defendem alfabetização dos surdos em escrita de sinais, ou seja, a alfabetização dos surdos em sua primeira língua (L1), para que posteriormente esses aprendizes possam aprender a escrita da língua oficial (QUADROS, 1997b). Porém, em nosso país, na esmagadora maioria dos casos, os surdos vão aprender a ler e escrever diretamente em português. A compreensão desse processo complexo de alfabetização e de aprendizagem da leitura em L2 desafia pesquisadores, já que os surdos aprendem a ler numa língua cujo sistema conceitual e estrutural difere de sua L1 e cujo sistema de escrita é baseado em relações grafofônicas. Ressalta-se ainda que os surdos têm atingido baixos níveis de leitura, como denunciado em várias pesquisas $^{2}$. Discutindo a questão da aquisição do inglês via escrita por surdos, Hoffmeister e Cadwell-Harris (2014) ${ }^{3}$ argumentam que uma explicação frequente para o baixo desempenho dos surdos em leitura é o acesso reduzido dos surdos à estrutura fonológica do inglês, mas que essa explicação se baseia numa perspectiva de estudos voltados para crianças ouvintes. Esses autores citam a metanálise realizada por

\footnotetext{
${ }^{2}$ No Brasil, por exemplo, o trabalho de Capovilla e colaboradores (2007) avalia, com uma bateria de testes, as habilidades de leitura de estudantes surdos de itens escritos individuais, comparativamente às habilidades de estudantes ouvintes. Além de identificar rotas de leitura diferenciadas entre os dois grupos, os autores relatam que a pontuação obtida por um aluno surdo de $4^{\mathrm{a}}$ série é aproximadamente equivalente à de um aluno ouvinte de $1^{a}$ série; já um surdo de $6^{a}$ série teria pontuação equivalente à de um ouvinte de $2^{\mathrm{a}}$ série; e a pontuação de um surdo de $8^{\mathrm{a}}$ série foi equivalente à pontuação de um ouvinte de $3^{\mathrm{a}}$ série. Ainda que a comparação com pessoas ouvintes seja limitada, já que o português é língua materna para ouvintes brasileiros e é a L2 para os surdos, tal procedimento permite vislumbrar, na falta de instrumentos de avaliação em L2, alguns resultados obtidos pelas pessoas surdas.

${ }^{3}$ Os autores propõem um modelo de aquisição do inglês via escrita por surdos profundos, discutindo a forma como a criança surda, usando a LS como ferramenta, pode mapear o significado do inglês escrito em estágios que dependem da forma como a criança consegue lidar com as diferenças entre as duas línguas.
} 
REVISTA X, Curitiba, volume 13, n.1,p. 206-229, 2018.

Dossiê Especial: Português como Língua Adicional em contextos de minorias:

(co)construindo sentidos a partir das margens

BIZON \& DINIZ (Orgs.)

Mayberry, del Giudice e Liberman (2011 apud HOFFMEISTER; CADWELLHARRIS, 2014) que aponta que a consciência fonológica apresenta apenas uma modesta relação com as habilidades em leitura. Focando no caso dos surdos profundos, Hoffmeister e Cadwell-Harris (2014) afirmam que, quando esses surdos estão diante da tarefa de ler em inglês - sem conhecer a gramática, palavras ou sons dessa língua, e alcançam sucesso -, eles o obtiveram por meio da língua escrita.

Muitos pesquisadores da área de educação de surdos no Brasil já concordam que a aprendizagem da escrita pode dispensar a consciência do som. Fernandes (2003), por exemplo, afirma que propor que o letramento da criança surda pode dispensar a "consciência do som" não é algo absolutamente novo. Em sua argumentação, a autora recorre a Vygotsky, o qual defende que "o desenvolvimento da escrita não repete a história do desenvolvimento da fala. A escrita é uma função lingüística que difere da fala oral tanto na estrutura como no funcionamento" (FERNANDES, 2003, p. 46).

É interessante notarmos a análise feita por Lacerda (1993) sobre como a relação entre a oralidade e a escrita tem sido observada em algumas práticas pedagógicas convencionais, as quais "preconizam o bom desempenho em linguagem oral como um dos itens necessários para a alfabetização" (LACERDA, 1993, p. 65). Pensando nessas questões e na análise de um caso de uma criança com deficiência ${ }^{4}$ em processo inicial de aprendizagem da escrita, podemos concluir que é necessário relativizar a dependência que se estabelece entre oralidade e escrita em alguns casos em que os alunos precisam aprender a escrita sem ter a consciência do som. Baseando-se em Vygotsky, essa autora explica que linguagem escrita seria

\begin{abstract}
inicialmente, um simbolismo de segunda ordem, porque tende a representar os sons da fala [...]. Lentamente, porém, desaparece a linguagem oral como elo intermediário entre a escrita e aquilo que ela representa, e a linguagem escrita passa a representar diretamente a realidade, tornando-se um simbolismo de primeira ordem (LACERDA, 1993, p. 67).
\end{abstract}

Além disso, Lacerda (1993) toma também o conceito de internalização de Vygotsky, a partir do qual explica como a criança se apropria de fenômenos sociais

\footnotetext{
${ }^{4}$ O sujeito analisado por Lacerda (1996, p. 69-70) "é um menino de nove anos, portador de um quadro de craniostenose, que trouxe como seqüelas [...], alterações em seu desenvolvimento motor refinado, tanto manual como orofacial, e uma alegada deficiência mental associada. A habilidade motora de Lu para falar apresenta-se comprometida configurando um quadro de dispraxia bucofacial".
} 
REVISTA X, Curitiba, volume 13, n.1, p. 206-229, 2018.

Dossiê Especial: Português como Língua Adicional em contextos de minorias:

(co)construindo sentidos a partir das margens

BIZON \& DINIZ (Orgs.)

através da linguagem, dos signos com os quais opera. Com base nessas explicações, pode-se refletir então que a criança surda deveria falar para que pudesse aprender a escrever. No entanto, no caso da pessoa surda, a ligação com a linguagem escrita se faz a partir da LS, assim como a internalização da escrita. A "fala será perfeitamente substituível por uma língua de sinais que desempenhará no surdo todas as funções cognitivas necessárias à alfabetização" (FERREIRA-BRITO, 1993, p. 7).

Referindo-se ao papel da Libras na aprendizagem do português pelo surdo, Pereira (2002, p. 49) afirma que "uma vez adquirida a língua de sinais, esta terá um papel fundamental na constituição do português, que será adquirido como segunda língua, preferencialmente, na modalidade escrita". Ainda segundo essa autora, é pela LS que os surdos adquirem o conhecimento de mundo com o qual dialogam com o material escrito, e é por meio também dessa língua que atribuem significado ao que leem, podendo deixar de ser meros decodificadores, passando a entrar na interação que se constrói pela linguagem. No processo de alfabetização e em outras práticas de letramento da pessoa surda, a LS serve para interpretar "duplamente" a língua escrita: interpretar e traduzir de uma língua para outra construindo sentidos (PEREIRA, 2002).

\section{Mediação da língua de sinais no ensino de leitura}

Constatando então o papel da LS para as crianças surdas em termos cognitivos e sociais, podemos vislumbrar melhor a importância do uso dessa língua como mediadora nos processos de ensino-aprendizagem. Porém, no caso do ensino da leitura, muitos trabalhos têm denunciado a forma como a Libras é utilizada de forma inadequada em sala de aula: discute-se como o uso de sinais da Libras para representar a estrutura do português escrito como única forma de se aproximar da escrita inviabiliza a construção de sentidos pelos alunos surdos e desvaloriza a língua da comunidade surda, relegandoa a mero instrumento para adquirir a língua de maior prestígio (LODI; HARRISON; CAMPOS, 2002; BOTELHO, 2002).

Essa denúncia está relacionada a uma tentativa de se desvencilhar de práticas comumente associadas com a abordagem educacional conhecida como Comunicação Total, em que o português sinalizado, em detrimento da LS, é utilizado como forma de comunicação em sala de aula. O português sinalizado, que seria um sistema artificial em 
REVIS T A X, Curitiba, volume 13, n.1,p. 206-229, 2018.

Dossiê Especial: Português como Língua Adicional em contextos de minorias:

(co)construindo sentidos a partir das margens

BIZON \& DINIZ (Orgs.)

que se usa o léxico da LS na estrutura sintática do português, bem como sinais inventados para representar elementos gramaticais do português (QUADROS, 1997a; GOLDFELD, 2002), vem sendo usado na educação das pessoas surdas no Brasil desde os anos 1980.

Conforme os críticos da Comunicação Total, a aparente aceitação do uso da LS apenas escamoteia a não-aceitação do uso dessa língua em sala de aula (FERREIRABRITO, 1993), sendo que o português sinalizado não permite uma comunicação satisfatória para os aprendizes surdos. Botelho (1998), por exemplo, explica que é necessário se questionar sobre o que realmente é compreendido pelos surdos a partir dessa forma de comunicação: “"Estou morrendo de frio' em português sinalizado faria supor que há alguém à beira da morte em razão do clima" (BOTELHO, 1998, p. 38). O uso desse sistema como principal forma de comunicação e no ensino da leitura e da escrita teve sérias consequências nas formas por meio das quais os surdos concebem a leitura e a escrita. Botelho (2002), por exemplo, denuncia o fato de que, mesmo quando a sinalização produzida durante a leitura constrói significados absurdos, os alunos surdos pesquisados por ela não se davam conta do que eles estavam dizendo em LS (BOTELHO, 2002, p.144).

Para além dos trabalhos que denunciam o uso do português sinalizado, vemos também, nos últimos anos, o desenvolvimento de trabalhos que pretendem compreender de que forma esse trânsito entre as duas línguas em sala de aula ocorre em sala de aula (SILVA, 2010, 2014) e de que forma estratégias pedagógicas conscientes podem ser empregadas de forma a potencializar a aprendizagem da leitura pelos estudantes surdos (ANDREWS; RUSHER, 2010; HOFFMAN; WOLSEY; ANDREWS; CLARK, 2017). Segundo Silva (2005, p. 53), o uso de mesclas em contextos de educação bilíngue tem sido uma grande polêmica: há que se considerar que as mesclas são comuns em contextos bilíngues e obedecem a certos padrões sociais; entretanto, relativamente a questões pedagógicas, Silva remete a Hamel (1989 apud SILVA, 2005) que afirma que a alternância de códigos no caso da educação bilíngue precisa obedecer a estratégias pedagógicas sistemáticas para viabilizar o processo de ensino-aprendizagem.

Considerando tais questões, abaixo: (i) apresentamos as mesclas como fenômenos naturais do bilinguismo, focando no caso do bilinguismo dos surdos; (ii) 
REVISTA X, Curitiba, volume 13, n.1, p. 206-229, 2018.

Dossiê Especial: Português como Língua Adicional em contextos de minorias:

(co)construindo sentidos a partir das margens

BIZON \& DINIZ (Orgs.)

para, nas seções seguintes, analisar um evento de leitura em sala de aula e apresentar estratégias visuais de ensino de leitura, que contemplam diferentes formas de usar a LS para se referir ao texto escrito.

\section{MESCLAS LINGUÍSTICAS}

Nos últimos anos, as definições de bilinguismo vêm-se ampliando, de perspectivas restritas, em que se considera o bilinguismo como o controle nativo de ambas as línguas, para perspectivas mais amplas, nas quais o bilinguismo é visto como um fenômeno multidimensional, em que a proficiência é um fator-chave para sua compreensão, mas não o único fator a ser considerado (LUK; BIALYSTOK, 2013). Grosjean (2008), por exemplo, define o bilinguismo como o uso de duas ou mais línguas no cotidiano. Nessa perspectiva, pode-se então conceber os surdos como sujeitos potencialmente bilíngues, que podem adquirir a LS da comunidade surda e a língua majoritária e usá-las em seu cotidiano para diversas funções, desenvolvendo diferentes níveis de proficiência.

Segundo Grosjean (2008), a perspectiva mais restrita de bilinguismo, focada na proficiência, advém de uma visão fracionada de bilinguismo, em que os bilíngues são inadvertidamente comparados a monolíngues, e fenômenos de mescla linguística são vistos como anômalos e resultado de interferências de uma língua sobre a outra. Ao contrário dessa visão fracionada dos bilíngues, o pesquisador propõe uma visão holística desses falantes, em que o bilíngue é visto de forma integrada, e não como a soma de dois monolíngues. Conforme propõe esse autor, a coexistência e interação entre as duas línguas dos bilíngues produzem um sistema linguístico diferente, mas completo, e podem ser vislumbradas, por exemplo, nos fenômenos de mescla linguística.

Assim como ocorre no bilinguismo de línguas faladas, no bilinguismo intermodal - ou seja, aquele que envolve duas línguas de modalidades diferentes -, também ocorrem fenômenos de mescla linguística como é o caso da alternância de línguas (code-switching), em que o bilíngue para de sinalizar (ou de falar) e começa a falar (ou sinalizar) (SOUSA; QUADROS, 2012). A alternância de línguas é um fenômeno de mescla que se manifesta linearmente. 
REVISTA X, Curitiba, volume 13, n.1, p. 206-229, 2018.

Dossiê Especial: Português como Língua Adicional em contextos de minorias:

(co)construindo sentidos a partir das margens

BIZON \& DINIZ (Orgs.)

Todavia, estudos vêm sendo conduzidos mostrando que, devido à não restrição articulatória, já que as duas línguas dos bilíngues intermodais dispõem de canais diferentes, esses bilíngues produzem sinais e palavras simultaneamente, o que foi chamado de sobreposição de línguas (code-blending). Essa sobreposição ocorre entre bilíngues intermodais surdos ou ouvintes, adultos ou crianças (ver revisão de EMMOREY et al., 2008). Ao tratar das mesclas no bilinguismo dos surdos, Grosjean (2008) destaca, como uma das diferenças dos bilíngues surdos, seus padrões de uso mais complexos. Conforme explica esse autor,

Quando um bilíngue de língua de sinais usa uma língua de sinais com um interlocutor, uma forma de língua falada sinalizada com outro, uma mescla de ambas com uma terceira, uma forma de comunicação simultânea (sinal e voz) com uma quarta, etc., os diversos comportamentos são o resultado de um número de fatores complexos [...] (GROSJEAN, 2008, p. 226) ${ }^{5}$

Essa complexidade dos padrões de conhecimentos e de usos das línguas dos bilíngues surdos se deve a vários fatores complexos, como: (i) o conhecimento da LS e da língua majoritária; (ii) os canais de produção (manual, oral e escrito) e a forma como servem às duas línguas; (iii) e a presença de outra língua num modo linguístico bilíngue (GROSJEAN, 2008, p. 226). O modo linguístico diz respeito aos níveis de ativação de ambas as línguas do bilíngue, o que vai depender de uma série de fatores, tais como o interlocutor, o tema da interação, etc.

Andrews e Rusher (2010), por exemplo, ao descreverem o uso das línguas por adultos surdos, destacam que os mesmos usam suas línguas de diferentes formas conforme (a) a pessoa com quem estão se comunicando; (b) o assunto sobre o qual estão falando; (c) e suas histórias linguísticas e educacionais. Esses autores explicam que os estudantes de graduação e colegas surdos tipicamente usam a Língua de Sinais Americana (American Sign Language - ASL) com seus colegas e alunos surdos, alternam para o inglês quando leem revistas, artigos ou quando se comunicam com ouvintes que não sabem LS. Alguns ainda usam formas de comunicação em que se mesclam sinais e inglês falado.

\footnotetext{
5 "When a sign language bilingual uses sign language with one interlocutor, a form of signed spoken language with another, a mixture of the two with a third, a form of simultaneous communication (sign and speech) with a fourth, etc., the diverse behaviors are the result of a number of complex factors [...]" (GROSJEAN, 2008, p.226)
} 
REVISTA X, Curitiba, volume 13, n.1,p. 206-229, 2018.

Dossiê Especial: Português como Língua Adicional em contextos de minorias:

(co)construindo sentidos a partir das margens

BIZON \& DINIZ (Orgs.)

Diferentemente dos adultos surdos citados no exemplo acima, que podem ter níveis de proficiência mais altos em ambas as línguas, as crianças surdas que estão adquirindo ambas as línguas não têm tais níveis e vão desenvolver as habilidades linguísticas conforme as características dos ambientes linguísticos aos quais têm acesso. Porém, conforme explicam Andrews e Rusher (2010), essas crianças podem ser consideradas bilíngues emergentes, que estão desenvolvendo suas duas línguas e outros modos de comunicação, inclusive o uso de mesclas.

Esses fenômenos naturais de mescla linguística, bem como o uso de sistemas manuais de representação das línguas faladas (como discutimos na seção anterior), precisam ser considerados ao se pensar as interações em sala de aula, inclusive no que tange às implicações para a aprendizagem dos alunos surdos, como discutiremos mais detidamente a seguir.

\section{UM EVENTO DE LEITURA DE UMA TURMA DE SURDOS}

Nesta seção, analiso um evento de leitura ocorrido numa turma de alunos surdos e professora ouvinte, do $9^{\circ}$ ano do Ensino Fundamental de uma escola pública de Belo Horizonte $^{6}$. Nesta turma, as aulas de leitura eram organizadas em diferentes etapas, sendo que a Libras era usada também de diferentes formas pelos participantes. Neste artigo, apresenta-se um pequeno excerto de uma aula em que a professora lia junto com os alunos um trecho do livro Lolo Barnabé, de Eva Furnari ${ }^{7}$. Anteriormente, a professora já havia pedido aos alunos que lessem o livro e solicitado que realizassem um trabalho com questões de interpretação de texto. Neste dia, ela explicava aos alunos o texto em Libras. Para isso, ela ia mostrando, nas transparências, as palavras e frases e sinalizava uma "tradução" do texto escrito. O objetivo da análise deste trecho é mostrar, por meio de exemplos reais da sala de aula, os desafios com que lidam professores e alunos quando necessitam transitar entre as duas línguas.

\footnotetext{
${ }^{6}$ Para mais análises das atividades de leitura deste grupo, ver Silva (2014 e no prelo).

${ }^{7}$ Apesar de não ser o foco deste trabalho, é importante mencionar os desafios encontrados por professores para selecionar textos compatíveis com os conhecimentos linguísticos dos alunos e com seus interesses conforme a faixa etária. Infelizmente, é bastante comum, no caso da educação de surdos, o uso de textos artificiais ou simplificados devido às dificuldades de alunos e professores na leitura de textos autênticos (SILVA, 2010).
} 
REVISTA X, Curitiba, volume 13, n.1,p. 206-229, 2018.

Dossiê Especial: Português como Língua Adicional em contextos de minorias:

(co)construindo sentidos a partir das margens

BIZON \& DINIZ (Orgs.)

No quadro 1, apresentamos as transcrições da aula de leitura, por meio do uso de glosas para representar as interações em Libras, basicamente utilizando e adaptando as convenções utilizadas por Quadros e Karnopp (2004), a saber: (1) as palavras em português escritas em maiúsculas buscam representar o conceito expresso pelo sinal; (2) quando duas ou mais palavras são necessárias para expressar esse conceito, essas foram ligadas por hífen; (3) as palavras realizadas em datilologia foram registradas em letras maiúsculas separadas por hífen; (4) os verbos foram representados por verbos no infinitivo, mesmo quando apresentavam flexão; (5) os verbos com concordância de pessoa foram representados no infinitivo juntamente com numerais que indicam o sujeito ou objeto. Os numerais indicam as três pessoas do discurso; (6) as expressões não-manuais foram indicadas logo após a palavra ou expressão em que aparecem. $\mathrm{O}$ trecho está indicado entre $(<>)$, seguido dos símbolos de pontuação correspondentes; (7) indicaram-se também alguns comentários entre colchetes.

A partir da análise da sinalização da professora apresentada no quadro 1, pode-se dizer que ela usa a Libras como língua de instrução nas aulas de leitura, dando acesso ao conteúdo do texto e explicando alguns trechos. Nesse processo, ela precisa traduzir o texto, fazendo escolhas sobre os sinais que vai usar para aproximar-se do significado em português. A professora enfatiza trechos do texto ao longo de sua explicação, inclusive devido à participação dos alunos. Nossa análise aponta para três aspectos que pretendemos destacar: (i) explicações sobre o significado de palavras; (ii) explicações sobre o significado de expressões; (iii) explicações sobre estruturas gramaticais do português. 
Dossiê Especial: Português como Língua Adicional em contextos de minorias:

(co)construindo sentidos a partir das margens

BIZON \& DINIZ (Orgs.)

Quadro 1 - Evento da aula de leitura do livro Lolo Barnabé

\begin{tabular}{|c|c|c|c|c|}
\hline \\
\hline $\begin{array}{l}\text { Texto em } \\
\text { português }\end{array}$ & Linha & Participação da professora & Participação dos alunos* & Comentários \\
\hline \multirow{3}{*}{$\begin{array}{l}\text { No tempo } \\
\text { em que as } \\
\text { pessoas } \\
\text { moravam } \\
\quad \text { em } \\
\text { cavernas, }\end{array}$} & 1 & $\begin{array}{l}\text { [a professora ia apontando com uma caneta na } \\
\text { transparência e sinalizando - não foi possível pegar o } \\
\text { que ela apontava] } \\
\text { PASSADO [movimento longo] }\end{array}$ & & $\begin{array}{l}\text { Faz o movimento do sinal PASSADO [com estalar de } \\
\text { dedos] de forma bem longa, enfatizando que era um } \\
\text { passado distante. }\end{array}$ \\
\hline & 2 & & R: MORAR & \\
\hline & 3 & $\begin{array}{llr}\text { PASSADO PESSOA MORAR MORRO } & \text { PEDRA } \\
\text { <LEMBRAR>? FILME JÁ HISTÓRIA } & \text { VÍDEO } \\
\text { (incompreensível) MORRO } & \text { PESSOA } & \text { CASA } \\
\text { MORRO PEDRA C-A-V-E-R-N-A } & \end{array}$ & & $\begin{array}{l}\text { A professora explica o significado da palavra caverna } \\
\text { para os alunos, buscando recuperar com eles seus } \\
\text { conhecimentos desse período histórico por meio de } \\
\text { filmes. O sinal escolhido pela professora para traduzir a } \\
\text { palavra caverna remete a morro, e não propriamente à } \\
\text { cavidade de uma caverna. }\end{array}$ \\
\hline \multirow{6}{*}{$\begin{array}{l}\text { existiu um } \\
\text { homem } \\
\text { muito } \\
\text { criativo e } \\
\text { inteligente } \\
\text { chamado } \\
\text { Lolo } \\
\text { Barnabé. }\end{array}$} & 4 & TER & & \\
\hline & & & $\begin{array}{l}\text { Vários alunos: HOMEM } \\
\text { R: SURGIR }\end{array}$ & \multirow{3}{*}{$\begin{array}{l}\mathrm{R} \text { interpreta a palavra criativo inicialmente como } \\
\text { "surgir", mas como o retorno da professora, já traz o } \\
\text { significado de "inventar". }\end{array}$} \\
\hline & 5 & [professora balança a cabeça em sinal negativo] & & \\
\hline & 6 & & R: INVENTAR & \\
\hline & 7 & $\begin{array}{l}\text { C-R-I-A-T-I-V-O INVENTAR [aponta para } \\
\text { quadro] INTELIGENTE C-H-A-M-A-D-O }\end{array}$ & $\begin{array}{l}\text { R: NOME } \\
\text { T: CHAMAR }\end{array}$ & $\begin{array}{l}\text { A professora associa a palavra criativo então ao sinal } \\
\text { relativo a criar, inventar. Logo em seguida, a professora } \\
\text { inicia a explicação sobre a palavra chamar. Dois alunos } \\
\text { interpretam essa palavra de forma diferente. }\end{array}$ \\
\hline & 8 & $\begin{array}{l}\text { [professora balança a cabeça em sinal negativo e faz } \\
\text { um gesto balançando a mão] (incompreensível) NÃOO }\end{array}$ & $\begin{array}{l}\mathrm{T} \text { : DOIS [aponta para o dedo } \\
\text { indicador e, em seguida, para o }\end{array}$ & $\begin{array}{l}\text { A professora explica que há dois significados diferentes } \\
\text { para o verbo chamar: chamar no sentido de nomear/ ter }\end{array}$ \\
\hline
\end{tabular}


Dossiê Especial: Português como Língua Adicional em contextos de minorias:

(co)construindo sentidos a partir das margens BIZON \& DINIZ (Orgs.)

\begin{tabular}{|c|c|c|c|c|}
\hline & & $\begin{array}{l}\text { DIFERENTE PRIMEIRO [indica enumeração em } \\
\text { Libras apontando, com o indicador da mão direita, o } \\
\text { indicador da mão esquerda] NOME LOLO } \\
\text { <ENTENDER>? DIFERENTE } \\
\text { EXEMPLO } \\
\text { PEDIR CHAMAR MARIA** EU <ENTENDER>? }\end{array}$ & $\begin{array}{l}\text { dedo médio, fazendo uma } \\
\text { enumeração, indicando que } \\
\text { havia dois significados para } \\
\text { chamar] }\end{array}$ & $\begin{array}{l}\text { um nome, e chamar no sentido de fazer vir. O aluno } \mathrm{T} \\
\text { confirma repetindo a indicação de dois significados para } \\
\text { a palavra chamar. }\end{array}$ \\
\hline & & $\begin{array}{l}\text { DOIS [aponta para o dedo indicador e, em seguida, } \\
\text { para o dedo médio, fazendo uma enumeração, } \\
\text { indicando que havia dois significados para chamar] } \\
\text { FRASE PERCEBER }\end{array}$ & $\begin{array}{l}\mathrm{R}: \mathrm{C} \text { [o aluno faz em } \\
\text { datilologia a letra C e fala em } \\
\text { português a palavra chamado } \\
\text { e, em seguida, faz o sinal] } \\
\text { NOME EXEMPLO [o aluno } \\
\text { fala em português "por favor } \\
\text { chama" e faz o sinal] POR- } \\
\text { FAVOR [a profa o interrompe] }\end{array}$ & $\begin{array}{l}\text { A professora conclui a explicação sobre os significados } \\
\text { do verbo chamar dizendo que o significado vai depender } \\
\text { da frase na qual está essa palavra. Porém, R parece não } \\
\text { ter compreendido a explicação e questiona sobre os } \\
\text { significados das duas formas do verbo - chamado e } \\
\text { chamar. Aparentemente o aluno tinha associado cada } \\
\text { forma verbal a um significado. }\end{array}$ \\
\hline & 9 & $\begin{array}{l}\text { ESPERAR [balança a cabeça negativamente] } \\
\text { EXEMPLO C-H-A-M-A MARIA }\end{array}$ & $\begin{array}{l}\mathrm{R}: \mathrm{A} \text { [o aluno faz em } \\
\text { datilologia a letra A e fala em } \\
\text { português a palavra chama }]\end{array}$ & $\begin{array}{l}\text { A professora explica que haveria duas formas do verbo: } \\
\text { uma relativa ao presente e outra ao passado. } O \text { aluno }\end{array}$ \\
\hline & 10 & C-H-A-M-O-U PASSADO MARIA & $\begin{array}{l}\mathrm{R}: \quad[\text { balança a cabeça } \\
\text { afirmativamente e diz } \mathrm{Ah} !]\end{array}$ & $\begin{array}{l}\text { demonstra ter compreendido, inclusive usando a língua } \\
\text { oral. }\end{array}$ \\
\hline & & $\begin{array}{l}\text { T } \\
\text { AMBÉM TER NOME FRASE }\end{array}$ & & $\begin{array}{l}\text { A professora parece indicar que logo depois do verbo vai } \\
\text { aparecer o nome de uma pessoa. }\end{array}$ \\
\hline $\begin{array}{l}\text { Aos vinte } \\
\text { anos, Lolo }\end{array}$ & 11 & [a profa. mostra na transparência um trecho] & $\begin{array}{l}\text { Vários alunos: VINTE } \\
\text { R: } 20 \text { IDADE }\end{array}$ & $\begin{array}{l}\text { Os alunos respondem à professora indicando o } \\
\text { significado da palavra apontada. }\end{array}$ \\
\hline $\begin{array}{l}\text { casou-se } \\
\text { com Brisa. }\end{array}$ & 12 & O-QUÊ? & $\begin{array}{l}\text { Vários alunos: ANOS } \\
\text { R: NÃO }\end{array}$ & $\begin{array}{l}\mathrm{C} \\
\text { om exceção de } \mathrm{R} \text {, os alunos atribuem à palavra anos o } \\
\text { significado de tempo transcorrido e não de idade de uma }\end{array}$ \\
\hline
\end{tabular}


Dossiê Especial: Português como Língua Adicional em contextos de minorias:

(co)construindo sentidos a partir das margens BIZON \& DINIZ (Orgs.)

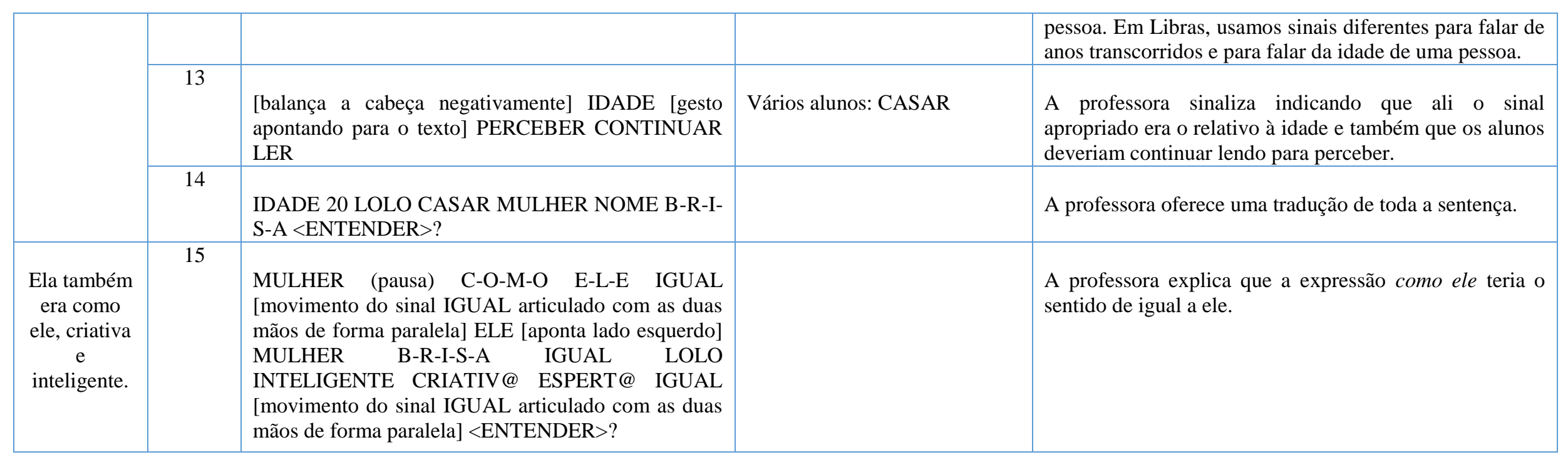

* Usamos iniciais para manter o anonimato dos alunos.

** A professora fez o sinal de identificação pessoal de uma intérprete da escola, cujo nome foi substituído por Maria, com vistas a garantir o anonimato. 
REVISTA X, Curitiba, volume 13, n.1,p. 206-229,2018.

Dossiê Especial: PLA em contextos de minorias: (co)construindo sentidos a partir das margens BIZON \& DINIZ (orgs.)

Referente à explicação sobre as palavras, trazemos os exemplos das palavras caverna e chamar. Como se pode observar na linha 3 do quadro 1, a professora oferece aos alunos uma tradução da palavra caverna, que seria "um morro de pedra onde as pessoas moravam". O sinal escolhido pela professora que transcrevemos como MORRO não corresponde ao item caverna, pois não traz a ideia de uma cavidade. Já no momento de explicar o trecho "chamado Lolo Barnabé" (linhas 7 a 10), a professora faz em alfabeto manual a palavra chamado, para que os alunos respondam atribuindo um sinal a essa palavra, mas os alunos respondem de forma diferente: (i) um aluno entende que a palavra corresponderia ao sinal NOME; e (ii) o outro sinaliza em Libras o verbo CHAMAR no sentido de fazer vir (linha 7). A professora então precisa explicar esses dois significados do verbo chamar, e indica aos alunos que eles vão precisar perceber o significado da palavra pela frase em que ela é empregada.

No que tange à explicação sobre as expressões, tratamos aqui das expressões "aos 20 anos" e "como ele". Nas interações transcritas nas linhas 12, 13 e 14, os alunos interpretam a expressão "aos 20 anos", como se tivessem transcorrido 20 anos, usando o sinal em Libras que indica duração de algo (linha 12). Contudo, a professora explica que ali se refere à idade (linha 14) e diz que os alunos devem continuar lendo para perceber o significado. Ao explicar a expressão "como ele", a professora usa o sinal IGUAL em Libras, realizando com as duas mãos, o que indica comparação.

No tocante à explicação sobre estruturas gramaticais, um aluno pergunta sobre a forma do verbo chamar (ver linha 8, 9 e 10), demandando da professora, além de uma explicação sobre o significado da palavra, um esclarecimento sobre a morfologia do verbo. A professora então explica que há a forma do verbo "chama" e a forma "chamou", que estaria no passado.

Esse excerto de uma aula de leitura nos coloca questões relativas à forma como os professores explicam em Libras os conteúdos de um texto em português e, ao mesmo tempo, podem criar oportunidades para que os alunos desenvolvam habilidades de leitura e conhecimentos linguísticos a serem usados na leitura de novos textos. Vamos tomar alguns exemplos para compreender melhor essa questão.

Tomemos o exemplo da palavra anos, que trouxe dificuldades de compreensão para os alunos (linha 12 do quadro 1). Em Libras, usamos dois sinais diferentes se 
REVISTA X, Curitiba, volume 13, n.1, p. 206-229,2018.

Dossiê Especial: PLA em contextos de minorias: (co)construindo sentidos a partir das margens BIZON \& DINIZ (orgs.)

vamos falar de nossa idade ou de anos transcorridos. A professora explica apenas que, naquele trecho do texto, eles deveriam usar o sinal IDADE, e não o sinal ANOS, mas não explica como a palavra anos pode ser interpretada pelos surdos dependendo da expressão em que está sendo utilizada (linha 13 do quadro 1). Nesse caso, as explicações dadas no nível da palavra não são suficientes para mostrar aos alunos a diferença entre os usos. A esse respeito, é importante pensar em como ir para além do nível da palavra com os alunos, fazendo as associações claras entre o que está escrito e o que se sinaliza, marcando visualmente essas unidades maiores do texto (expressões, frases, etc.) que podem ser objeto da explicação em Libras. A explicação sobre a expressão "como ele" também é extremamente curta e se resume a oferecer aos alunos uma tradução, de modo que a estrutura mais complexa Ela também era como ele não é explicada aos alunos.

Ressalta-se que a professora oferece uma boa tradução da expressão para os alunos, explorando o espaço da sinalização em Libras (ver linha 15 do quadro 1). Porém, novamente, poderíamos pensar numa explicação que tome como objeto a expressão $\mathrm{X}+$ verbo ser + como + Y, em que X e Y são comparados. Em LS, essa comparação pode ser feita por meio da localização dos dois referentes em pontos diferentes no espaço e o uso do sinal IGUAL nas duas mãos, cada uma localizada nesses pontos de localização dos referentes.

Como se pode perceber, tanto a explicação sobre a palavra anos e expressões associadas como a explicação sobre a expressão Ela também era como ele poderiam ser realizadas por meio da análise comparativa ${ }^{8}$ entre a Libras e português. Dessa forma, os alunos não teriam simplesmente acesso ao conteúdo do texto, mas poderiam desenvolver conhecimentos linguísticos sobre palavras, expressões e estruturas do português. Nesse sentido, vale ressaltar também como a explicação sobre o tempo verbal do verbo chamar nas linhas 9 e 10 não contempla o particípio do verbo que ocorre no texto. A professora simplesmente explica que teria dois tempos verbais presente e passado, mas não chama a atenção para a forma usada no texto - chamado. Nesse sentido, provavelmente, uma análise textual da narrativa poderia ter sido adotada pela professora, mostrando como essa forma verbal é comum no início de narrativas ao

\footnotetext{
${ }^{8}$ Discutiremos isso mais detidamente na próxima seção.
} 
REVISTA X, Curitiba, volume 13, n.1,p. 206-229,2018.

Dossiê Especial: PLA em contextos de minorias: (co)construindo sentidos a partir das margens BIZON \& DINIZ (orgs.)

se apresentarem os personagens, o que articularia aspectos textuais (apresentação dos personagens), semânticos (significados do verbo chamar) e estruturais do português (uso do particípio).

Considerando os aspectos analisados aqui, passamos então à próxima seção para se apresentar como se podem adotar estratégias visuais de ensino da leitura, observando de forma consciente o uso da LS por professores e alunos durante as aulas de leitura.

\section{ESTRATÉGIAS VISUAIS DE ENSINO DA LEITURA}

Quando os professores sinalizam trechos de textos, explicando aos aprendizes surdos o conteúdo ou algum elemento linguístico dos textos, há dois aspectos importantes a serem considerados: (i) de que forma ligar a explicação oferecida em Libras ao objeto da explicação de forma visual para o aprendiz surdo?; (ii) como verter o conteúdo do texto em português usando a Libras, ou seja, que tipo de "tradução" ou estratégia o professor deve utilizar? $\mathrm{Na}$ tentativa de construir um paradigma visual de ensino da leitura, Andrews e Rusher (2010) propuseram o uso de alguns termos para estratégias orientadas para o ensino da leitura.

\footnotetext{
Nós também usamos o termo alternância de línguas (code-switcbing) para representar uma estratégia de ensino planejada e dirigida por um propósito, a ser usada pelo professor. Em nossa pesquisa sobre leitura, nós usamos o termo storysigning (sinalização da história) como uma alternância de língua no nível da história ou do discurso narrativo. A sinalização da história ocorre quando o professor traduz de forma livre para a ASL a história escrita em inglês (Nover \& Andrews, 2000; Simms, Andrews, \& Smith, 2005). Outra estratégia da alternância de língua usada na aula de leitura é chamada de leitura da história (storyreading). Essa estratégia é usada quando um professor oferece uma tradução sentença por sentença para a ASL de uma história escrita em inglês com o objetivo de fazer uma tradução mais literal. Gallimore (2000) cunhou o termo "fingerscanning" (escaneamento com os dedos) para descrever uma ferramenta prática para mostrar que um evento de alternância de línguas está prestes a acontecer. De acordo com Gallimore, quando o professor coloca seu dedo sob a escrita em inglês, esse ato físico indica ao aluno surdo que uma tradução em ASL da palavra ou sentença está por acontecer. Esses termos representam nossa tentativa de desenvolver um paradigma visual de aquisição de leitura no caso de crianças surdas sinalizantes. (ANDREWS; RUSHER, 2010, p.410) ${ }^{9}$
}

\footnotetext{
${ }^{9}$ Tradução livre do original: "We also use the term codeswitcbing to represent a purpose-driven and planned instructional strategy used by the teacher. In our reading research, we use the term storysigning to mean codeswitching at the story or narrative-discourse level. Storysigning occurs when the teacher freely translates a story written in English to ASL (Nover \& Andrews, 2000; Simms, Andrews, \& Smith, 2005). Another codeswitching strategy used in the reading classroom is called storyreading. This
} 
REVISTA X, Curitiba, volume 13, n.1,p. 206-229,2018.

Dossiê Especial: PLA em contextos de minorias: (co)construindo sentidos a partir das margens BIZON \& DINIZ (orgs.)

Os autores recorrem a um termo comumente usado em pesquisas da área do bilinguismo - alternância de línguas (code-switching) - para se referir a outro conceito - as estratégias de ensino planejadas e usadas pelo professor que envolvem o trânsito entre as línguas em sala de aula. Além disso, também propõem diferentes formas de sinalizar o texto escrito, de modo que os alunos possam ter acesso ao texto por meio de uma tradução livre e de uma tradução literal. Tais estratégias são importantes no ensino da leitura para surdos, pois dão oportunidade ao aluno surdo: (i) por meio da tradução literal, de visualizar estruturas linguísticas da língua escrita via representação manual dessa língua; (ii) por meio da tradução livre, de acessar o conteúdo e construir os sentidos do texto, observando inclusive como as palavras se agrupam e se articulam e podem trazer novos significados.

Outro ponto apontado na citação é o uso do escaneamento do texto, em que o professor aponta uma palavra ou o início de uma expressão que será traduzida para a LS, fazendo uma ponte entre o escrito e o sinalizado. Essa estratégia liga visualmente o escrito e o sinalizado, identificando assim o objeto da explicação em andamento.

A tradução do texto, seja uma tradução literal ou uma tradução livre, é uma importante estratégia que precisa ser considerada com propósitos bem definidos, tais como: "comparar e contrastar características de cada língua, compreender significado implícito no texto, explicar múltiplos significados de palavras e sinais. Seu objetivo é ajudar os estudantes a compreender significado e forma" (VISUAL LANGUAGE \& VISUAL LEARNING, 2012, p. 4) ${ }^{10}$. Essa ressalva a respeito da tradução se faz necessária para que não se crie uma dependência dos alunos para acessar sua língua

strategy is used when the teacher provides a sentence-by-sentence translation into ASL of a story written in English in order to make the translation more literal. Gallimore (2000) has coined the term fingerscanning to describe a handy tool for signaling that a codeswitching event is about to happen. According to Gallimore, when the teacher places his or her finger under the English print, this physical act signals to the deaf student that an ASL translation of the word or sentence is imminent. These terms represent our attempt to develop a visual paradigm of reading acquisition for signing deaf children". (ANDREWS; RUSHER, 2010, p.410)

10 Tradução livre do original: "Translation is used to compare and contrast the characteristics of each language, to understand implicit meaning in text, and to explain the multiple meaning of words and signs. Its aim is to help students understand both meaning and form." (VISUAL LANGUAGE \& VISUAL LEARNING, 2012, p. 4). 
REVISTA X, Curitiba, volume 13, n.1,p. 206-229,2018.

Dossiê Especial: PLA em contextos de minorias: (co)construindo sentidos a partir das margens BIZON \& DINIZ (orgs.)

menos desenvolvida, diminuindo a efetividade da tradução como prática bilíngue (VISUAL LANGUAGE \& VISUAL LEARNING, 2012).

Interessante observar que essa tradução literal que seria usada em momentos específicos do ensino da leitura poderia ser, no caso do ensino de português para surdos, o português sinalizado. Diferente do uso denunciado por autores citados anteriormente (LODI; HARRISON; CAMPOS, 2002; BOTELHO, 2002), o uso do português sinalizado nesta proposta não é a única forma de interação em sala de aula nem a única forma de aproximação do texto escrito. Ao contrário, essa estratégia é usada em momentos específicos e de forma consciente pelo professor para representar manual e visualmente determinadas expressões ou estruturas, construindo uma primeira ponte entre o escrito e o sinalizado, de forma a focar na forma desses elementos linguísticos para, então, em outro momento, explicar seu significado usando uma tradução livre, ou seja, usando a LS.

Andrews e Rusher (2010), por meio da apresentação de um exemplo de aula de leitura, mostram como poderiam ser empregadas tais técnicas. Abaixo apresentamos uma síntese esquemática dessa possível aula.

\section{Quadro 2 - Possível aula de leitura}

Uma possível aula de leitura
(1) O professor planeja a aula, considerando: (i) como integrar LS e língua escrita; (ii)
como apresentar visualmente o texto aos alunos.
(2) Estudantes surdos leem os textos e discutem entre si em LS, tendo uma oportunidade
de preencher lacunas conceituais e de conhecimento de mundo.
(3) O professor projeta um trecho do texto para os alunos e dá tempo para que leiam.
(4) Em seguida, retira a projeção e oferece aos alunos uma tradução livre de uma parte
do texto.
(5) Os alunos questionam o professor sobre algum aspecto de sua tradução e então ele
retoma o trecho, apontando no quadro (fingerscanning) e sinalizando de forma literal.
(6) O professor explica sua tradução livre com comparações gramaticais entre a língua
escrita e a LS.
(7) O professor pede aos alunos que se revezem sinalizando/ traduzindo o texto para o
grupo.
(8) Quando eles têm dificuldade em algum trecho, os colegas os auxiliam.

Fonte: Andrews e Rusher (2010) 
REVISTA X, Curitiba, volume 13, n.1,p. 206-229,2018.

Dossiê Especial: PLA em contextos de minorias: (co)construindo sentidos a partir das margens BIZON \& DINIZ (orgs.)

Cada etapa da aula de leitura relatada no quadro (2) nos indica como certos aspectos do ensino visual da língua escrita podem ser abordados ${ }^{11}$. Como se vê nos itens (1) e (3), o professor se preocupa em projetar o texto para os alunos. Apesar de aparentemente simples, essa é uma estratégia essencial na educação de surdos, muitas vezes ignorada especialmente em salas de aula inclusivas: enquanto para os alunos ouvintes, é comum simultaneamente ler o texto, olhando para a folha ou para o caderno, e ouvir o que o professor está explicando; para os surdos, isso não é possível já que eles usam os olhos para ler e ver a sinalização da professora. A disponibilização visual de textos permite que os alunos olhem para os textos e para o professor, além de permitir também que alunos e professores se remetam a elementos do texto durante as aulas, apontando e marcando trechos.

Outro aspecto da aula que merece destaque é a construção coletiva dos sentidos do texto: em vários momentos da aula (ver itens 2, 5, 7 e 9 do quadro 2), o professor estimula a interação entre alunos, bem como a interação entre esses e o próprio professor, possibilitando que os surdos construam sentidos por meio da LS, língua compartilhada por professor e alunos. Essas estratégias empoderam os estudantes ao permitir que usem sua própria língua na relação com o texto escrito e compreendam o texto a partir de seu referencial linguístico (ANDREWS; RUSHER, 2010). Chamo a atenção para o item (4) da aula, em que o professor retira a projeção do texto para oferecer aos alunos uma tradução livre e, em seguida, no item (5) retoma a projeção. Essa estratégia de retirar a projeção (item 4) é particularmente interessante, pois comunica aos alunos que o importante, neste momento, é observarem o conteúdo do trecho sinalizado, e não sua forma. A forma linguística será objeto de explicação posteriormente, como ocorre nos itens (5), (6) e (9) da aula descrita no quadro 2. Nesses momentos, o professor recorre a comparações entre a LS e a língua escrita, tornando a língua escrita mais compreensível pelos aprendizes surdos e contribuindo na construção de conhecimentos linguísticos por esses aprendizes.

\footnotetext{
${ }^{11}$ É importante esclarecer que essa possível aula apresentada no quadro 2 cf. Andrews e Rusher (2010) não é uma sequência a ser seguida de forma rígida. $\mathrm{O}$ objetivo dos autores, assim como o nosso neste artigo, é mostrar um exemplo de aula, que pode ser modificada conforme o gênero ou tipo de texto trabalhado, os objetivos do ensino de leitura, o nível de complexidade do texto, entre outros aspectos.
} 
REVISTA X, Curitiba, volume 13, n.1,p. 206-229,2018.

Dossiê Especial: PLA em contextos de minorias: (co)construindo sentidos a partir das margens BIZON \& DINIZ (orgs.)

A análise comparativa entre línguas ou análise contrastiva (QUADROS, 1997a; SVARTHOLM, 1999; SILVA, no prelo) é uma importante estratégia de ensino de língua escrita para surdos, pois possibilita aos aprendizes refletir sobre o funcionamento de suas duas línguas e aprender a ler. Conforme as palavras de Svartholm (1999, p. 19) ao se referir ao caso das crianças suecas: "É dessa forma que as crianças surdas aprendem a ler: aprender a ler e aprender a língua sueca se torna um e o mesmo processo". Se retomarmos a análise do evento de leitura apresentado na seção 4, podemos compreender melhor como essa análise comparativa pode compor a aula de leitura, contribuindo para o desenvolvimento de conhecimentos linguísticos dos aprendizes surdos. Como expliquei anteriormente na análise do evento apresentado no quadro 1 , o ideal seria que a professora tivesse empregado a análise comparativa para explicar a palavra anos e as expressões que continham tal palavra, bem como a expressão Ela era como ele, usando para isso comparações com as formas linguísticas em Libras.

Nesses usos da LS que vão sendo construídos em sala de aula, é importante considerar os padrões de uso linguístico da comunidade surda que são mais complexos do que no bilinguismo de línguas faladas (GROSJEAN, 2008). Como propõem Hoffman e colaboradores (2017), é importante se guiar por uma epistemologia surda para se compreender o letramento e o ensino para surdos, podendo potencializar, por meio de estratégias "nativas" desse grupo, o ensino de leitura. Hoffman e colaboradores (2017) buscam explorar como ocorrem os processos de leitura para esse grupo por meio de uma pesquisa com surdos adultos fluentes em inglês e ASL e a partir de uma perspectiva teórica voltada para a compreensão de práticas translíngues. Num processo de análise comprometido com uma perspectiva êmica, os autores discutem alguns aspectos que aparecem nas entrevistas, tal como o uso da tradução realizado pelos surdos. Para os participantes, o processo de compreensão foi diferenciado quando sinalizaram os textos, sendo que os participantes desta pesquisa não sinalizavam os textos na ordem do inglês. Além da tradução, os autores descrevem também outras práticas de trânsito entre as línguas. 


\begin{abstract}
A força da translinguagem foi vista quando os participantes usaram várias estratégias: uma foi seu conhecimento prévio sobre ser surdo; outra foi a expansão das ideias do texto em inglês por meio da ASL para permitir conexões com o conhecimento geral em ASL, e finalmente seu uso de expansões de ASL e sinais lexicais da ASL para prover uma transformação da estrutura do inglês em um texto compreensível em ASL. Vários participantes até falaram com o texto, realizando perguntas retóricas depois de ler uma frase para ajudá-los a construir o significado e também falaram sobre o texto sinalizando "IMPRESSIONANTE", depois de ler uma idéia que compreenderam e acharam interessante [...] Frequentemente, os participantes focaram em morfemas gramaticais da ASL, incluindo expressões faciais, movimentos de cabeça, deslocamento do corpo, perguntas retóricas e classificadores. Esse uso mostra a consciência metalinguística de suas duas línguas para transmitir o significado do texto de uma forma compreensível (Ausbrooks et al., 2014). (HOFFMAN et al., 2017) ${ }^{12}$
\end{abstract}

Como Hoffman e colaboradores (2017) apontam, a compreensão da forma como os surdos com boas habilidades nas duas línguas leem pode informar os estudos sobre o ensino da leitura para surdos, inclusive sobre aspectos culturais a serem considerados no ensino.

\title{
CONSIDERAÇÕES FINAIS
}

Neste trabalho, buscamos mostrar como, ao longo das práticas de leitura, alunos surdos e professores precisam transitar entre a LS e a língua escrita na sala de aula, lidando com as diferenças linguísticas entre essas duas línguas. A análise do evento de ensino de leitura buscou evidenciar a complexidade do trabalho do professor de português para surdos, especialmente no que tange à forma como usa a LS para estimular o processo de construção de sentidos pelos alunos e explicar diferentes elementos linguísticos dos textos em português. A descrição da proposta de um paradigma visual de leitura cf. Andrews e Rusher (2010) visou apresentar formas de

\footnotetext{
${ }^{12}$ Tradução livre do original: "The strength of translanguage was seen when the participants used several strategies; one was their background knowledge about being Deaf, another was the expansion of the ideas in the English text through ASL to allow connections to general knowledge in ASL, and finally their use of ASL expansions and ASL lexical signs to provide a transformation of the English structure into a comprehensible ASL text. Several participants even talked to the text by asking rhetorical questions after reading a sentence to assist them in deriving meaning and also talked about the text by signing "AWESOME" after reading an idea that was he was comprehending and one he found exciting [...] Frequently, the participants focused on ASL grammatical morphemes, including facial expressions, nodding, body shifts, rhetorical questions, and classifiers. This usage showed their metalinguistic awareness of both of their languages to convey the meaning of the text in a comprehensible format" (Ausbrooks et al., 2014) (HOFFMAN et al., 2017, p. 1937)
} 
REVISTA X, Curitiba, volume 13, n.1,p. 206-229,2018.

Dossiê Especial: PLA em contextos de minorias: (co)construindo sentidos a partir das margens BIZON \& DINIZ (orgs.)

lidar com o trânsito entre línguas de forma sistematizada em termos de objetivos de ensino. Como explicamos, as mesclas são fenômenos naturais do bilinguismo e estarão presentes na sala de aula. Porém, cabe ao professor observar seu uso e buscar estratégias para potencializar a aprendizagem pelos surdos.

O modo como se compreende o fenômeno do bilinguismo numa perspectiva holística (GROSJEAN, 2008), inclusive as crianças surdas como bilíngues emergentes que podem se beneficiar de práticas que exploram suas duas línguas de forma integrada (ANDREWS; RUSHER, 2010), pode contribuir significativamente para a construção de estratégias visuais de ensino da leitura que sejam efetivas para esses bilíngues, além de contribuir com o desenvolvimento da competência bilíngue dos surdos. Destaca-se como essas práticas também podem estar comprometidas com uma perspectiva surda de ensino da leitura (HOFFMAN et al., 2017), explorando as práticas culturais de trânsito de línguas da própria comunidade surda.

\section{REFERÊNCIAS}

ANDREWS, J. F.; RUSHER, M. Codeswitching Techniques: evidence-based instructional practices for the ASL/English Bilingual classroom. American Annals of the Deaf. v.155, n.4, p. 407-424, 2010.

BOTELHO, P. Leitura e Surdez. In: I Seminário sobre linguagem, leitura e escrita de surdos, 1998, Belo Horizonte. CEALE/ Anais do I Seminário sobre linguagem, leitura e escrita de surdos. Belo Horizonte: FaE/UFMG, 1998. p.136-145.

BOTELHO, P. Linguagem e Letramento na Educação de Surdos: ideologias e práticas pedagógicas. Belo Horizonte: Autêntica, 2002.

CAPOVIlla, F. C.; CAPOVILlA, A. G. S.; MACEDO, E. C. (Tele)avaliando o desenvolvimento da competência de leitura em ouvintes e surdos de escolas especiais e comuns: o estado da arte. In: MIOTTO, E. C.; LUCIA, M. C. S.; SCAFF, M. (Org.), Neuropsicologia e as interfaces com as neurociências. São Paulo, SP: HCUSP, 2007, p. 229-240.

EMMOREY, K.; BORINSTEIN, H. B.; THOMPSON, R.; GOLLAN, T. H. Bimodal bilingualism. Bilingualism: Language and Cognition, v. 11, n. 1, p. 43 - 61, mar. 2008.

FERNANDES, E. Linguagem e Surdez. Porto Alegre: Artmed, 2003. 
REVISTA X, Curitiba, volume 13, n.1,p. 206-229,2018.

Dossiê Especial: PLA em contextos de minorias: (co)construindo sentidos a partir das margens BIZON \& DINIZ (orgs.)

FERREIRA-BRITO, L. F. Integração social \& educação de surdos. Rio de Janeiro: Babel, 1993.

GOLDFELD, M. A criança surda: linguagem e cognição numa perspectiva sociointeracionista. São Paulo: Plexus Editora, 2002.

GROSJEAN, F. Studying Bilinguals. Oxford/ New York: Oxford University Press, 2008.

HAMEL, R. E. Determinantes sociolinguísticas de la educatión indígena bilingüe. Trabalhos em Lingüística Aplicada, v.14, p.15-66,1989.

HOFFMAN, D.; WOLSEY, J.; ANDREWS, J.; CLARK, D. Translanguaging Supports Reading with Deaf Adult Bilinguals: A Qualitative Approach. The Qualitative Report, vol. 22, n.7, p. 1925-1944, 2017.

HOFFMEISTER, R. J.; CADWELL-HARRIS, C. L. Acquiring English as a second language via print: The task for deaf children. Cognition, v. 132, n.2, p. 229-242, 2014.

LACERDA, Cristina B. Feitosa de. É preciso falar bem para escrever bem? In: SMOLKA, A. Luiza B.; GÓES, M. C R. de. A linguagem e o outro no espaço escolar. Vygotsky e a construção do conhecimento. Campinas: Papirus, 1993, p. 65-100.

LODI, A. C. B. A Leitura em Segunda Língua: práticas de linguagem constitutivas da(s) subjetividade(s) de um grupo de surdos adultos Cad. Cedes, Campinas, vol. 26, n. 69, p. 185-204, maio/ago. 2006.

LODI, A. C. B.; HARRISON, K. M. P.; CAMPOS, S. R. L. Letramento e Surdez: um olhar sobre as particularidades dentro do contexto educacional. In: LODI, A. C. B.; HARRISON, K. M. P.; CAMPOS, S. R. L.; TESKE, O. (Org.). Letramento e Minorias. Porto Alegre: Mediação, 2002. p. 35-46.

LUK, G.; BIALYSTOK, E. Bilingualism is not a categorical variable: Interaction between language proficiency and usage. Journal of Cognitive Psychology, v. 25, n.5, p. 605-621, 2013.

MAYBERRY, R. I., DEL GIUDICE, A. A.; LIEBERMAN, A. M. Reading Achievement in Relation to Phonological Coding and Awareness in Deaf Readers: A Meta-analysis, The Journal of Deaf Studies and Deaf Education, v. 16, n. 2, p. 164$188,2011$.

PEREIRA, M. C. C. Papel da língua de sinais na aquisição da escrita por estudantes surdos. In: LODI, A. C. B.; HARRISON, K. M. P.; CAMPOS, S. R. L.; TESKE, O. (Orgs). Letramento e Minorias. Porto Alegre: Mediação, 2002. p. 47-55. 
REVISTA X, Curitiba, volume 13, n.1,p. 206-229,2018.

Dossiê Especial: PLA em contextos de minorias: (co)construindo sentidos a partir das margens BIZON \& DINIZ (orgs.)

QUADROS, R. M. Educação de surdos: a aquisição da linguagem. Porto Alegre: Artes Médicas, 1997a. 126 p.

QUADROS, R. M. de. Aquisição de L1 e L2: o contexto da pessoa surda. In: Seminário Desafios e Possibilidades na Educação Bilíngue para Surdos, jul. 1997, Rio de Janeiro. Anais... Rio de Janeiro: INES, Divisão de Estudos e Pesquisas - Rio de Janeiro: Ed. Líttera Maciel Ltda, 1997b, p.70-87.

QUADROS, R. M.; KARNOPP, L. Língua de sinais brasileira: estudos linguísticos. Porto Alegre: Artes Médicas, 2004.

SILVA, G. M. Lendo e sinalizando textos: uma análise etnográfica das práticas de leitura em português de uma turma de alunos surdos. Dissertação (Mestrado em Educação) - Faculdade de Educação, Universidade Federal de Minas Gerais, Belo Horizonte, 2010.

SILVA, G. M. O processo de ensino-aprendizagem da leitura em uma turma de alunos surdos: uma análise das interações mediadas pela Libras. Revista Brasileira de Linguística Aplicada, v. 14, n. 4, p. 905-934, 2014.

SILVA, G. M. Interações em sala de aula e o processo de ensino-aprendizagem da leitura em português no caso de aprendizes surdos. In: SILVA, I. R.; SILVA, M. P. M. (orgs.) Letramento na diversidade: surdos aprendendo a ler/escrever. Campinas: Mercado de Letras (no prelo).

SILVA, I. As representações do surdo na escola e na família: entre a (in)visibilização da diferença e da "deficiência". 2005. 280 f. Tese (Doutorado em Linguística Aplicada) - Instituto de Estudos da Linguagem, Universidade Estadual de Campinas/ UNICAMP. Campinas, 2005.

SOUSA, A. N.; QUADROS, R. M. de. Uma análise do fenômeno "alternância de línguas" na fala de bilíngues intermodais (Libras e Português). ReVEL, v. 10, n. 19, p. 327-346, 2012.

SVARTHOLM, K. Bilingüismo dos Surdos. In: SKLIAR, C. (org.). Atualidade da Educação Bilíngüe para Surdos. $2^{\mathrm{a}}$ ed. Porto Alegre: Mediação, 1999, v.2, p.15-23.

VISUAL LANGUAGE AND VISUAL LEARNING SCIENCE OF LEARNING CENTER. ASL/English Bilingual Education (Research Brief No. 8). Washington, DC: Maribel Gárate, junho de 2012. 